\title{
Surface Roughness Control Simulation of Turning Processes
}

\author{
Franci Čuš - Uroš Župerl* \\ University of Maribor, Faculty of Mechanical Engineering, Slovenia
}

The aim of this paper is to present a surface roughness control in turning with an associated simulation block diagram. The objective of the new model based controller is to assure the desired surface roughness by adjusting the machining parameters and maintaining a constant cutting force. It modifies the feed rate on-line to keep the surface roughness constant and to make machining more efficient. The control model was developed based on simplified models of the turning process and the feed drive servo-system. The experiments were performed to find the correlation between surface roughness and cutting forces in turning and to provide functional correlation with the controllable factors. Simulation setup and results are presented to demonstrate the efficiency of the proposed control model. In terms of surface roughness fluctuations and cutting efficiency, the suggested control model is much better than a conventional CNC controller alone. Integrating the developed control model with the CNC machine controller significantly improves the quality of machined components.

Keywords: machining, turning, surface roughness, model based control, simulation

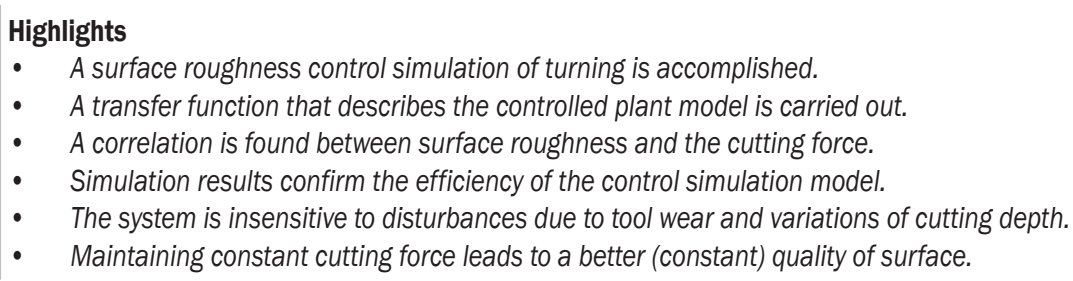

- A surface roughness control simulation of turning is accomplished.

- A transfer function that describes the controlled plant model is carried out.

- A correlation is found between surface roughness and the cutting force.

- Simulation results confirm the efficiency of the control simulation model.

- The system is insensitive to disturbances due to tool wear and variations of cutting depth.

- Maintaining constant cutting force leads to a better (constant) quality of surface.

\section{O INTRODUCTION}

The machining quality on computerized numerically controlled (CNC) machine tools is sensitive to the machining parameters. With modern machine tools, an operator still manually adjusts controlling parameters, such as feed rate and cutting speed. The adjusted values mainly depend on operator experience and knowledge. Standard machining catalogues and commercial cutting condition prediction software [1] generally offer only recommended values, which are far from optimum. Usually, technicians set the highest feed rate possible. The limitations are the available machine power, tool strength and surface roughness tolerance. The increase of the cutting force due to the higher feed rates increase the tool and work piece deflection, machine chatter; consequently, work piece precision is reduced. Therefore, maintaining the cutting force on the tool tip at the appropriate value is a method to ensure dimensional accuracy. To solve this problem, it is necessary to modify the controlling parameters on-line [2]. Adaptive control (AC) accomplishes this. The AC of turning operations is a logical continuance of the evolution of $\mathrm{CNC}$ systems. The goal of adaptive control is to control the turning process via the on-line adjusting of controlling parameters [3], which are subject to machining constraints. An AC system is introduced in the cutting process by Stute and Goetz [4].
Such systems to maximize the feed rate for a specified cutting force in turning operations have been proposed in the past [5]. Many AC systems that employed on-line adjustment of the feed rate to ensure a stable and efficient turning have been proposed [6] and [7]. Thus far, no control system has been proposed to adjust cutting condition to maintain surface roughness constant in prescribed tolerances.

Model reference adaptive control (MRAC) systems have been also developed for turning [8]. MRAC systems, developed from AC theory, are widely used due to their robustness and disturbance rejection capability. The basic adaptive model reference adaptive controller approach was originally investigated by Landers and Ulsoy [9]. These controllers were simulated and evaluated and physically implemented by [10]. Numerous forms of MRAC system have been developed, especially in milling [11] and [12]. Non-deterministic MRAC controllers are not always suitable for real time control [13] because the controller requires an explicit model and significant computation. The neural network-based MRAC systems [14] and [15] allow much faster development of the models and thus make these controllers practical. The main drawback of integrating MRAC systems in turning is that many algorithms generate significant oscillatory behaviour at low depths of cutting [10]. The model-based control system developed in our research overcomes this 
problem by employing off-line numerical simulations. Via simulations, the performance and stability of the control system are determined. The optimum control parameters for turning have been investigated. Via simulations, we also attempted to determine if the proposed control model has been justified for all test conditions. The proposed control model is conceived in such a way that there is no need to perform complicated modelling since the simulations depend only on easily measurable cutting force signals.

Recent studies show that force signals contained the most useful information for determining the output process variables, especially surface roughness [16].

However, in many cases, the use of force sensors is not practical for retrofit applications and the spindle power signal is often used as an alternative. By analysing the cutting force characteristics, it is possible to assess the changes in the quality of surface finish [17]. Therefore, the experiments were performed to find the correlation between surface roughness and the resultant cutting force. Correlations found for various machining conditions are incorporated into simulation models.

The resulting control model maintains an almost constant surface roughness throughout the cutting process regardless of the work piece material used, cutting tool and machining parameters, especially depth of cutting.

In this paper, an AC system is described for turning on a lathe with a constant cutting force constraint. The detailed structure of an adaptive surface control system for turning is presented. The model based controller modifies the feed rate on-line in order to keep the surface roughness constant and to maintain the cutting efficiency. Due to the very encouraging simulation results, the control model has been implemented successfully on a commercial lathe. The experimental results from an actual machining operation will be presented in the future work.

\section{STRUCTURE OF ADAPTIVE CONTROL SYSTEM}

The idea of this research is to implement on-line $\mathrm{AC}$ in conjunction with an off-line cutting condition prediction algorithm.

A model-based control system is a controller that modifies its behaviour in response to change in the dynamics of the process.

The structure of the proposed control system of turning is presented in Fig. 1. The system consists of a cutting conditions prediction model, a reference, a comparison block and control block, a cutting process, a CNC servo system, a feed rate override command element and a sensor that measures the output process variable.

The defined constraints of all output process variables are fed into the comparison block. Then they are compared with current feed values and send to the control block. The control block algorithm adapts cutting parameters in such a way that it improves the cutting tool life and surface roughness.

The objective of the proposed control is, therefore, to adjust the feed rate in order to maintain the turning resultant cutting force and surface roughness as constant. If the resultant cutting force is maintained as constant during the process of turning, then the surface finish also remains stable. In order to control the process, force information must be available to the control algorithm at every $10 \mathrm{~ms}$. LabVIEW data acquisition software is used to

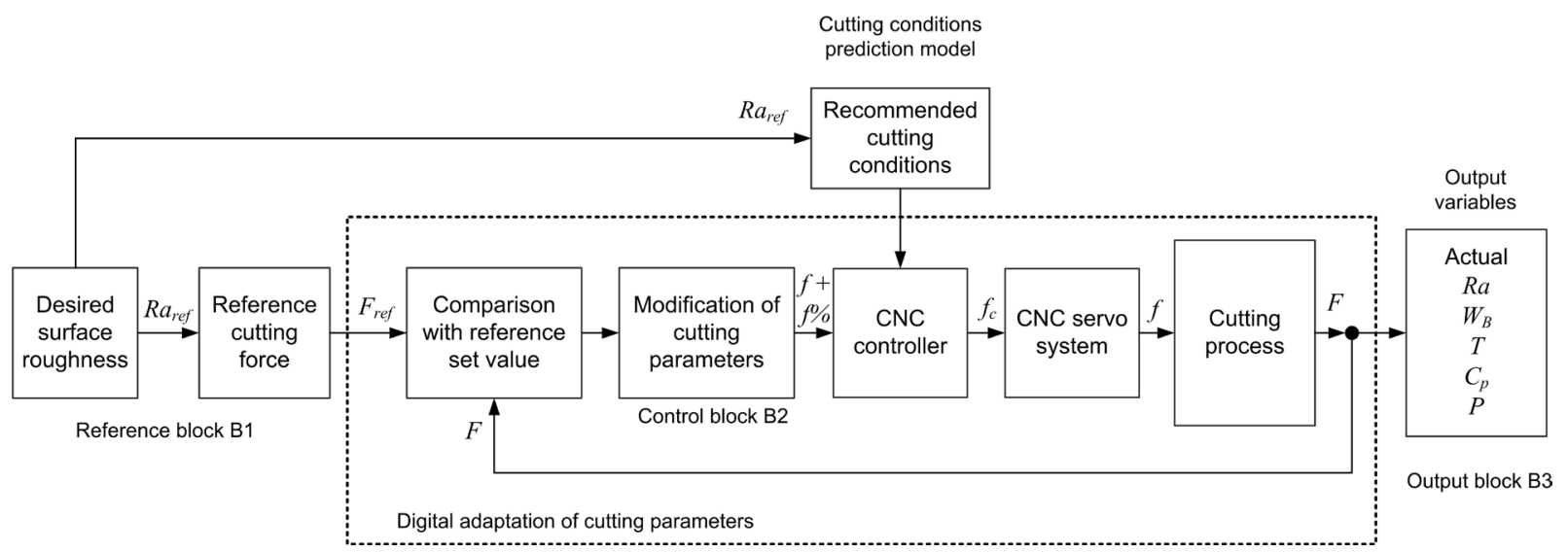

Fig. 1. Structure of surface roughness control in turning 
provide this information. The cutting force resultant is obtained using a Kistler force dynamometer. These measured cutting force signals are used in the control model to regulate the surface roughness.

The command feed rate calculated from the control model algorithm is converted to a percentage of the programmed feed rate. The control model adjusts the feed rate by assigning an override percentage to the $\mathrm{CNC}$ controller of the turning machine, based on a measured cutting force. The actual feed rate is the product of the feed rate override percentage $f \%$ and the recommended feed rate $f$.

The output block determines output process variables ( $W_{B}$ tool wear [18], $T$ tool life, $C_{P}$ operation cost, $F$ resultant cutting force).

A simulation block diagram for testing the stability and fine tuning of the control parameters is developed. After simulations, the control model can be installed on real CNC turning machine tool.

\subsection{Sequence of Steps for Adaptive Control of Turning Process}

The sequence of steps for surface roughness control of the turning process is presented below.

1. The desired value $R a_{r e f}$ is initiated;

2. Based on desired $R a_{r e f}$, the recommended cutting conditions are determined off-line by an artificial neural network model [19];

3. Based on desired $R a_{r e f}$, the reference force $F_{\text {ref }}$ is predicted according to the reference block $\mathrm{B} 1$;

4. When the force $F_{r e f}$ is known, the command value $f_{c}$ is determined;

5. The other recommended cutting conditions are sent to the $\mathrm{CNC}$ of the machine tool;

6. The measured resultant cutting forces are compared with reference value and sent to the control (block for modification of cutting parameters);

7. Actual $R a$ is determined based on the measured cutting force $F$;

8. The control block adjusts the feed rates and sends it back to the machine;

9. Steps 6 to 9 are repeated until termination of machining.

The algorithm of the proposed control structure is presented in Fig. 2.

The objective of control algorithm is to adjust the turning process parameters to achieve the required values of surface finish.

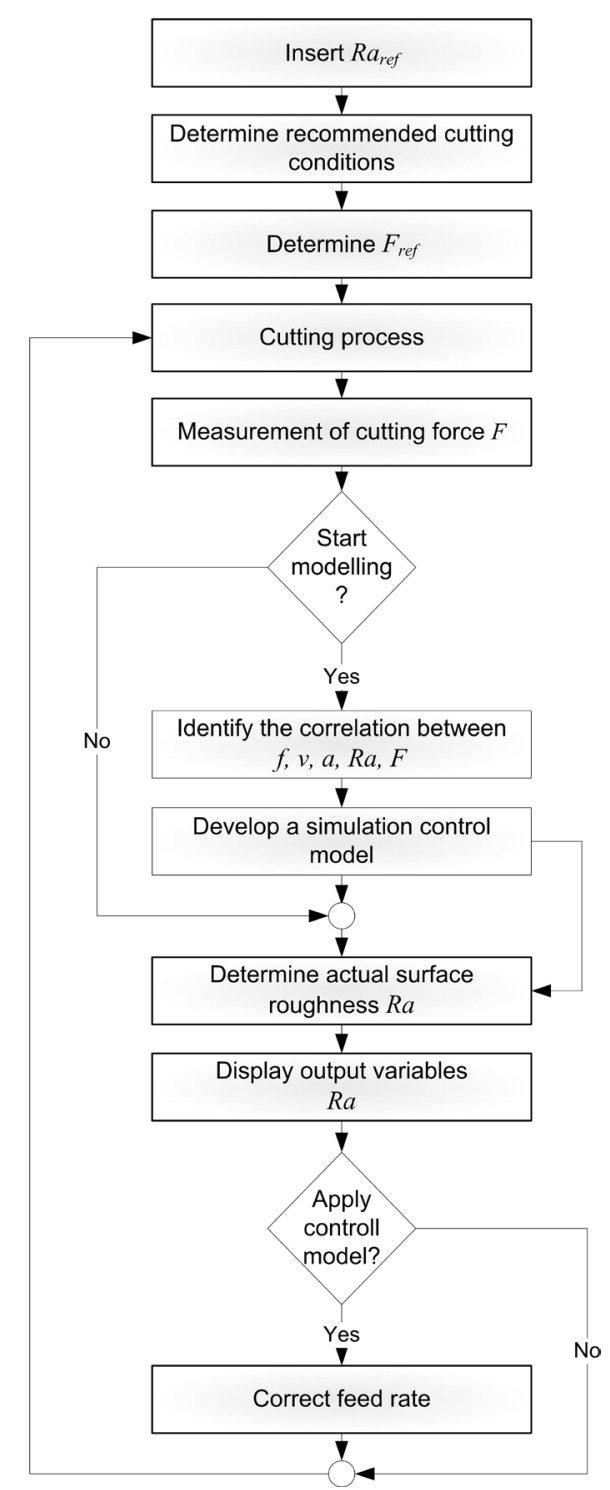

Fig. 2. Flow chart of adaptive surface roughness control

\section{CONTROL MODEL SIMULATION BLOCK DIAGRAM}

The block diagram of the proposed control model is presented in Fig. 3. It enables a closed loop control of cutting force and thus produces a desired surface roughness in turning.

The simulator input is the desired surface roughness, and the output is the actual surface quality.

The control model is developed in Matlab Simulink. It comprises of simulator of cutting, a simulator of the feed servo-drive, a reference block, an output variables block, a block for modification of cutting parameters and the models determining the mutual relations between influencing cutting 


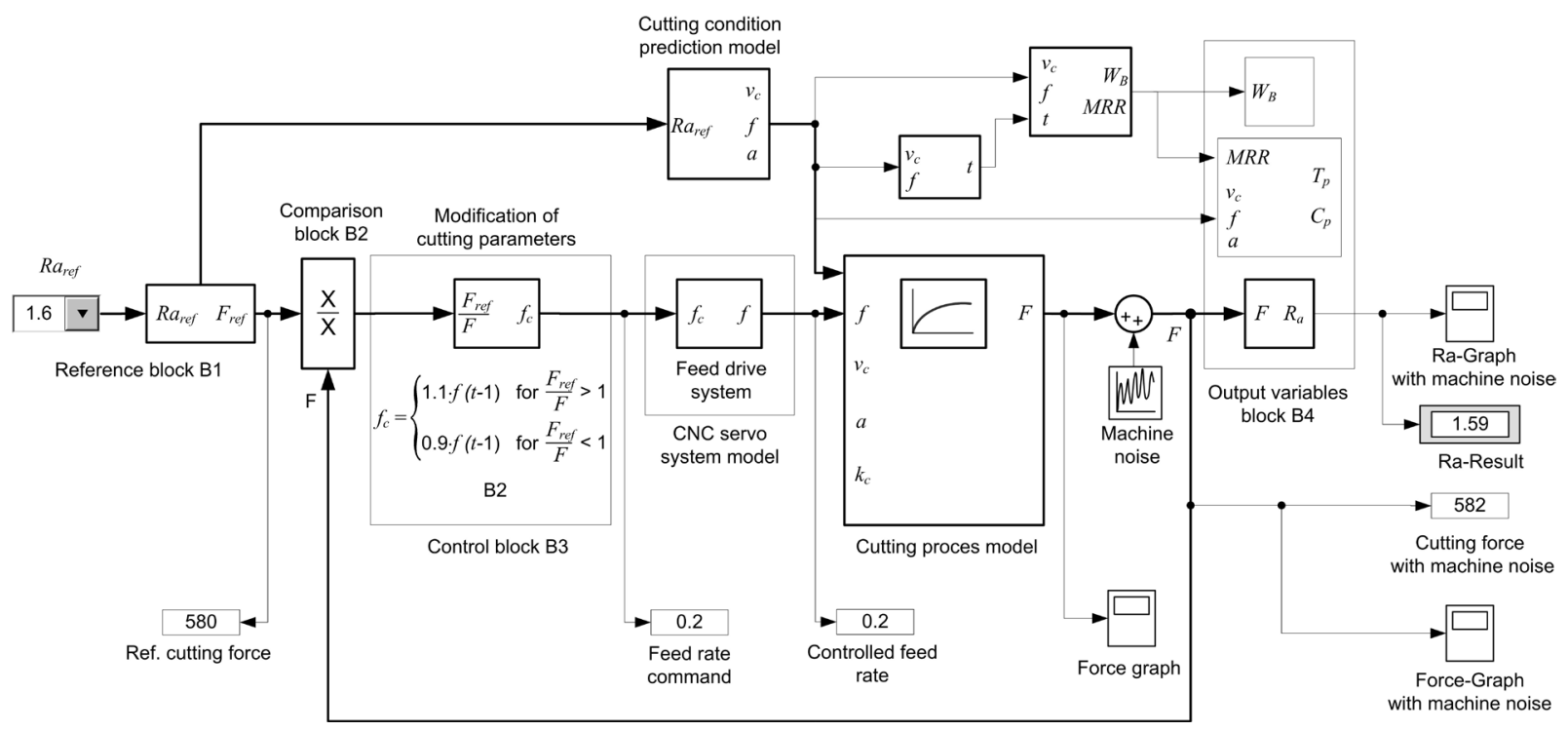

Fig. 3. Simulation block diagram for the surface roughness control model

quantities. These elements describe the dynamics of the control model.

The objective of the block for the modification of cutting parameters is to minimize control errors and to provide the appropriate feed rate for a specific machining situation.

Digital adjustment of feed rate is accomplished in such a way that the output process variable is first compared with the reference value. If the value of actual $R a$ exceeds the desired surface roughness $R a_{r e f}$, then the control algorithm immediately reduces the feed rate in order to reduce the produced surface roughness, while the cutting speed remains constant.

If the value of actual $R a$ does not reach the desired surface roughness, then the control algorithm immediately increases the feed rate. The plant to be controlled includes the cutting process and the $\mathrm{CNC}$ servo system.

The machine tool used in the study was a typical $\mathrm{CNC}$ lathe controlled by a $\mathrm{CNC}$ whose model allows feed rate override commands ranging from $0 \%$ to $150 \%$.

The cutting process and the CNC servo system model can be represented as:

$$
\begin{gathered}
H_{p}(s)=\frac{F(s)}{f(s)}=\frac{k_{c} \cdot a}{n} \cdot \frac{1}{1+t_{c} \cdot s}, \\
H_{s}(s)=\frac{f(s)}{f_{c}(s)}=\frac{1}{1+t_{s} \cdot s},
\end{gathered}
$$

where $n$ is the spindle speed in [rpm], $k_{c}$ is the specific cutting force $\left[\mathrm{N} / \mathrm{mm}^{2}\right], a$ is the depth of cut, $t_{c}$ is the time constant of the cutting process, and $t_{s}$ is the time constant of the CNC servo system.

The feed servo-drive model simulates the machine response to changes in the desired feed rate. The objective of the feed servo-drive system is to minimize the error and provide the appropriate and actual feed rate for a specific machining situation.

The step response of the CNC system used in our research is shown in Fig. 4. The pre-programmed feed rate $(0.2)$ is overridden from $0 \%$ to $150 \%$. The time to reach 0.632 of the step input is found graphically. The time constant $t_{s}$ is measured to be $0.13 \mathrm{~s}$.

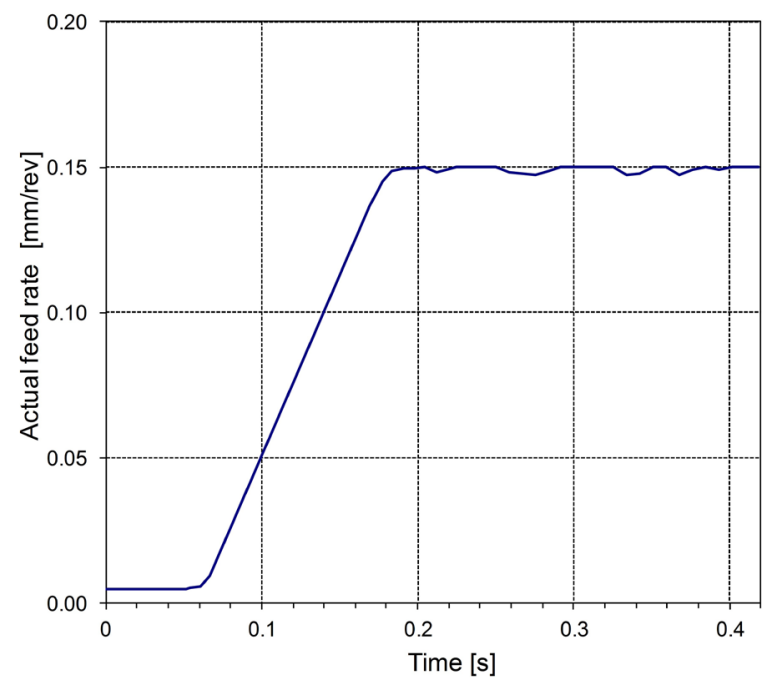

Fig. 4. Step response of the $x$-axis feed drive system 
The whole turning plant system can be represented with the transfer function:

$$
H(s)=\frac{1}{n} \cdot \frac{k_{c} \cdot a}{1+\left(0.13+t_{c}\right) \cdot s+0.13 \cdot t_{c} \cdot s^{2}} .
$$

The uncontrollable measurement noise is not included in the above transfer function due to the difficulties of describing its random nature mathematically.

The transfer functions of the machine dynamics are based on the technical specifications of the GF NDM 16 CNC lathe.

The predicting models of the output variables developed in this work are based on experimental results performed in research [20].

The experimental datum contains the value of the predicted (modelled) quantity and the relevant influencing parameters (cutting parameters). Statistical and mathematical modelling is used to provide functional relationships with the most important parameters and variables, i.e. feed rate, spindle speed, surface roughness and the resultant cutting force.

The results of modelling are the simulation models, which can be easily included into the Simulink simulation package. These models are depicted in Fig. 3.

Prior machining the required quality of the surface finish $R a_{r e f}$ is defined. The model defining the correlation between the desired surface roughness and the appurtenant resultant cutting force is labelled as M1.

In order to develop the M1 model, the experiments were carried out for all combinations of the chosen parameters that significantly affect the turning process. These input parameters are cutting conditions, depth of cut, feed rate, and cutting speed. Other parameters, such as cutting tool geometry, type of raw material, etc., are kept constant for the scope of this study. A total of 1500 combinations of input parameters (depth of cut, feedrate, and spindle speed) were selected to measure cutting forces and the corresponding roughness of the machined surface.

The measurements of the tool wear during machining were not carried out, despite the fact that it has a significant effect on the rise of cutting force and on the achieved surface roughness. The aim of this study is to take into account the tool condition in the prediction of cutting forces without expensive inprocess tool wear measurements.

Recent studies show that cutting force signals and the surface roughness values contain the most useful information for determining the tool condition (tool wear) [5]. Therefore, the influence of the tool wear in the prediction of cutting forces is captured indirectly through increased surface roughness due to changes of the cutting edge geometry.

Based on the values of these 1500 experimental data, the relation between the cutting force and the surface roughness was determined according to Eq. (4). This equation was obtained by using single regression formula for steel machining at low depths of cut.

$$
\begin{aligned}
F_{r e f} & =-279.26 \cdot R a_{r e f}^{5}+2946.9 \cdot R a_{r e f}{ }^{4}- \\
& -12032 \cdot R a_{r e f}{ }^{3}+23636 \cdot R a_{r e f}^{2}- \\
& -22062 \cdot R a_{r e f}+8250.8 .
\end{aligned}
$$

Eq. (4) determines the reference cutting force necessary to reach and maintain the desired surface roughness regardless of the cutting tool condition. It indirectly takes into account the condition of the tool in the calculation of cutting forces.

The output variables block (B4) tests if the simulated $R a$ corresponds with the desired $R a$. The produced surface roughness was calculated from the above mentioned experimental data according to Eq. (5):

$$
R a=0.2401 \cdot e^{0.0034 \cdot F} .
$$

Similar to Eq. (4), Eq. (5) is obtained by using an exponential regression formula. Both equations are based on the same experimental data.

The outputs of block B4 were also compared to the predictions of the artificial neural network surface roughness model developed by [21]. The predictive capability of the block B4 and neural network approach is compared using statistics, which showed that neural network predictions for surface roughness were only $2 \%$ closer to the experimental measurements, in comparison to block B4.

A much simpler and faster B4 is used in the simulation model, despite the lower accuracy of predictions.

When the simulation model of the feed drive system (shown in Fig. 3) and the simulator of cutting process are replaced by the real machine tool, a harmonized system for dynamic adjustment of feed rate is obtained.

The system with an adjustment of feed rate override assures the required surface roughness. The following algorithm is used to on-line adjust the feed rate. 


$$
f_{c}=\left\{\begin{array}{ll}
1.1 \cdot f(t-1) & \text { for } \frac{F_{r e f}}{F}>1 \\
0.9 \cdot f(t-1) & \text { for } \frac{F_{r e f}}{F}<1
\end{array}\right\} \text {, }
$$

where, $f_{c}$ is a feed rate command $[\mathrm{mm} / \mathrm{rev}]$, and $f(t-1)$ previous actual feed rate command.

This algorithm determines the optimal feed rate required to obtain the controllable surface roughness.

\section{SIMULATION RESULTS AND DISCUSSION}

Via simulations, the efficiency and stability of the control model with different requirements of the surface quality are tested. The criterion for the efficiency of the control model is the difference between the desired and simulated $R a$.

The starting cutting conditions and the desired $R a_{\text {ref }}$ are the input data.

The following paragraphs present the simulation example (Sim. No. 1 and Sim. No. 3; Table 1) in which the model-based control was applied to demonstrate its performance. The simulation outputs are shown in Fig. 5.

Recommended cutting conditions for each cut are first determined off-line, and then simulation tests are made without and with control model action. The recommended cutting parameters are determined with the prediction model [19]. The spindle speed is set at $610 \mathrm{rpm}$, and the resultant cutting force undergoes random changes up to $10 \%$. The simulation time is
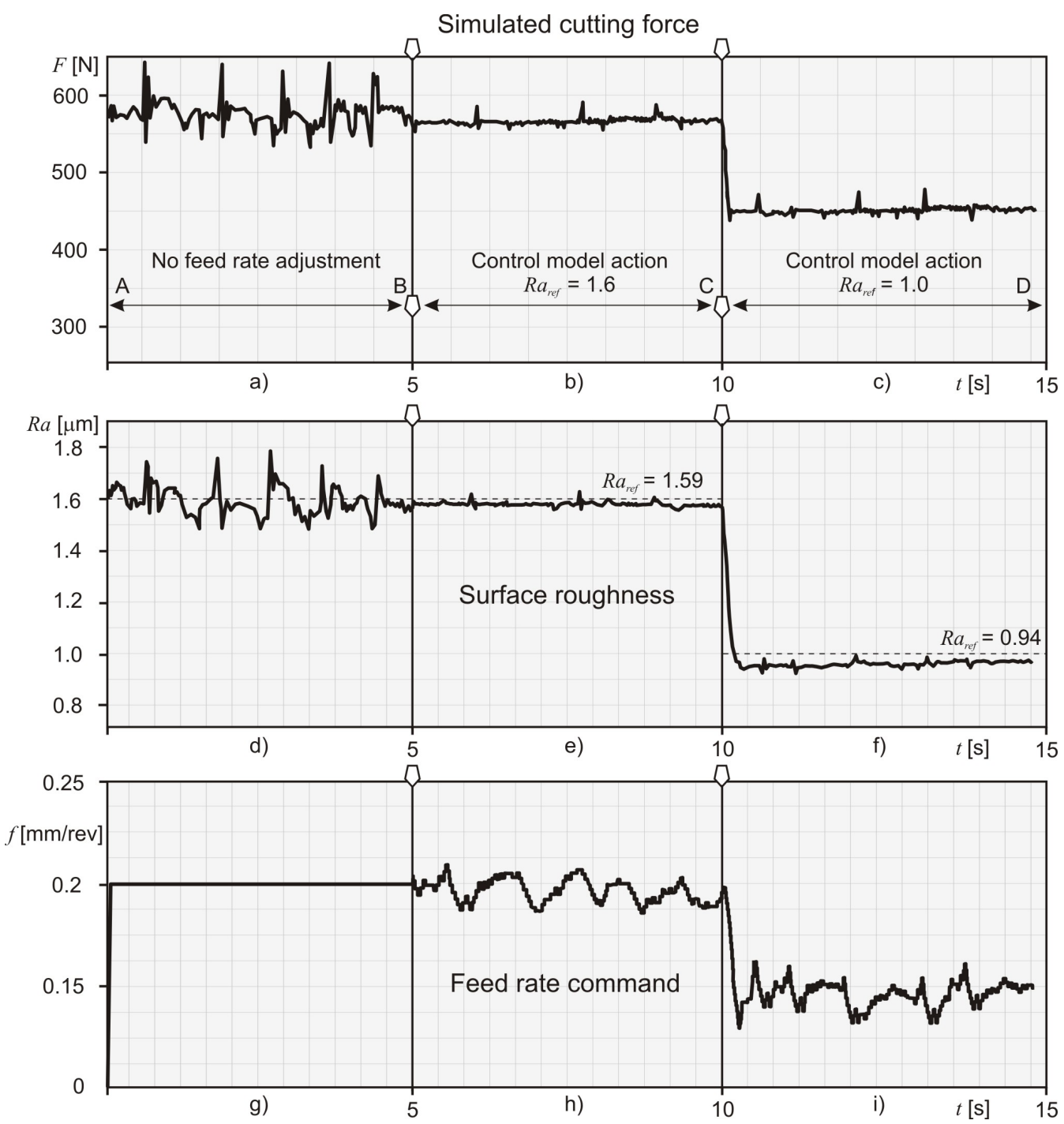

Fig. 5. Simulated control model response with in without feed rate adjustment 
Table 1. The simulation requirements and result

\begin{tabular}{ccccccc}
\hline \multirow{2}{*}{ Sim. No. } & $\begin{array}{c}\text { Desired surface } \\
\text { roughness } \\
R a_{\text {ref }}[\mathrm{mm}]\end{array}$ & \multicolumn{2}{c}{ Results without control model action } & \multicolumn{2}{c}{ Results with control model action } \\
\cline { 2 - 7 } & $\mathbf{1 . 0}$ & $F[\mathrm{~N}]$ & $f[\mathrm{~mm} / \mathrm{rev}]$ & $F[\mathrm{~N}]$ & $f[\mathrm{~mm} / \mathrm{rev}]$ & $\begin{array}{c}\text { Actual surface } \\
\text { roughness } R a[\mathrm{~mm}]\end{array}$ \\
\hline $\mathbf{1}$ & 1.3 & $\mathbf{4 6 0 . 6 3}$ & $\mathbf{0 . 1 7}$ & $\mathbf{4 4 8 . 0 6}$ & $\mathbf{0 . 1 5}$ & $\mathbf{0 . 9 5}$ \\
\hline 2 & $\mathbf{1 . 6}$ & $\mathbf{5 5 6 5 . 5 4}$ & 0.18 & 522.86 & 0.17 & 1.28 \\
\hline $\mathbf{3}$ & 1.9 & 628.78 & 0.23 & 615.5 & 0.22 & $\mathbf{1 . 5 9}$ \\
\hline 4 & 2.2 & 641.5 & 0.24 & 638.28 & 0.23 & 2.1 \\
\hline 5 & 2.5 & 661.83 & 0.25 & 683.73 & 0.25 & 2.45 \\
\hline 6 & 2.8 & 735.77 & 0.28 & 727.0 & 0.27 & 2.77 \\
\hline 7 & 3.1 & 762.35 & 0.29 & 750.0 & 0.28 & 2.98 \\
\hline 8 & & & & & $\mathbf{0 . 2}$ & \\
\hline
\end{tabular}

$15 \mathrm{~s}$. In Table 1, the requirements and the results of simulations are indicated.

The undesirable aspects of the experimental results of the measured cutting forces were represented by the model of machine noise, which is shown on Fig. 3. This model has been generated to simulate the uncontrollable measurement noise resulting especially from the non-homogeneity of raw material, tool wear and tool breakage. The machine noise model is generated by using a random of variation, which relates to the settings of cutting force data acquisition software. It adds noise in the simulation model in order to test the reference of the output with the effect of the noise. When the noise is eliminated from the model, an ideal simulation result was obtained.

The signals of resultant cutting force and the quality of surface are mutually related and have identical trends.

Fig. $5 \mathrm{~d}$ and e show the surface roughness of the workpiece without and with control model action. The $R a$ in Fig. 5d is not constant when machining without control action, because the feed rate is not adjusted when the output exceeds the reference value.

Fig. $5 d$ is the response of the surface roughness where there is no feed rate adjustment. The $R a$ is constant when using dynamic adjusting of feed rates (Fig. 5d; Section B to D).

The control model is initiated by the selection of the reference value $R a_{r e f}$; afterwards, reference cutting force $F_{r e f}$ is predicted according to reference block B1. To use the proposed control system and to adjust the feed rate, the desired surface roughness is $1.6 \mathrm{~mm}$, the recommended feed is $0.2 \mathrm{~mm} / \mathrm{rev}$ and its allowable adjusting rate is [0\% to $150 \%]$.

The data of simulation example is marked as No. 3 and is presented in Table 1. The depth of cutting was set to $1 \mathrm{~mm}$. When the reference force is known, the command value $f_{c}$ is determined according to the $\mathrm{B} 3$ block. The initial value $f_{c}$ is $0.2 \mathrm{~mm} / \mathrm{rev}$, thus allowing the feed to be overridden from $0 \mathrm{~mm} / \mathrm{rev}$ to 0.3 $\mathrm{mm} / \mathrm{rev}$

The control bock is changing the initial value $f_{c}$, until the optimum controlled feed rate of 0.2 $\mathrm{mm} / \mathrm{rev}$ has been reached. The $\mathrm{CNC}$ servo drive model generates the actual feed rate $f$ from the command signal $f_{c}$. Dynamic adjustment of feeding is a prerequisite for maintaining constant surface roughness of $1.6 \mathrm{~mm}$.

The actual $R a$ is determined by the output variables block B4. The result is a roughness of 1.59 $\mathrm{mm}$, which is acceptable if compared with the desired value of $1.6 \mathrm{~mm}$ (Fig. 5e).

In the first simulation using constant feed rates the $R a$ reaches its proper value only in the last second of Sections A and B (Fig. 5d). However, by applying control action, the average $R a$ achieved is much more close to the reference $R a$. It reaches and maintains the value of $1.59 \mathrm{~mm}$ (Fig. 5e).

The resultant cutting force for the control model is maintained at about $570 \mathrm{~N}$ (Fig. 5b).

The control system responds to the fall of the desired $R a$ by immediate reduction of feeding (Fig. 5f; Section $\mathrm{C}$ to $\mathrm{D}$ ). As a result, the cutting force drops to value of $448 \mathrm{~N}$ (Fig. 5c). It can be seen that by continuously adjusting the feed rate (section B to D), the cutting force is maintained at a constant so that the desired surface roughness can be attained.

The results confirm that the proposed control model is efficient in obtaining the desired surface roughness and that it is efficient in fine machining. Constant cutting forces lead to better surface quality.

Although the system remains stable in all performed simulation tests, one obvious problem appears if the measured resultant cutting force approaches zero. In this situation, the feed rate command values would increase to infinity. A very 
small value of cutting force would lead to incorrect increase in the feed rate, causing excessive forces when the tool enters the workpiece.

This problem has been efficiently eliminated by restricting the controller action to sample periods when the measured forces are above a certain userspecified threshold for a specified time. In our study, the threshold to start the control action is set to be 100 $\mathrm{N}$.

This solution ensures that the control algorithm is activated only when the tool is engaged in the workpiece. When the forces are bellow a userdefined threshold, the tool is assumed to be out of the work piece, and the control actions are paused. The developed solution also includes the restrictions of the control actions for feedrates limited by chip thickness.

After simulations, the simulation model of CNC servo system (shown in Fig. 5) and the simulator of cutting process were replaced by the real $\mathrm{CNC}$ machine tool GF NDM 16. The performance of the suggested system was then verified by a serial of experimental works on the lathe for $\mathrm{Ck} 45$ steel workpieces with variation of cutting conditions. The machine tool was connected with a personal computer. The connection was designed to allow GF NDM16 to be under digital control implemented in the PC. The model control was developed in Matlab. The experimental testing results are not described in this paper.

\section{CONCLUSION}

In this research, the model-based controller is proposed to control the turning process with constant surface roughness. The control model modifies the feed rate in real time in order to keep the surface roughness constant and to make machining more efficient.

The surface roughness control model was developed based on the simplified models of the feed drive servo system and the turning process.

The correlation between the process output variables (cutting forces, surface roughness) and cutting parameters is determined by using statistics. A high degree of correlation is found between surface roughness and the resultant cutting forces for various machining conditions.

The effects of the developed control model on $R a$ control have been studied through simulations. They have shown that the proposed control model makes the system insensitive to disturbances due to tool wear, non-homogeneity of work piece material and variations of depth of cutting.
The performance of the developed control model is much better in comparison to classic $\mathrm{CNC}$ turning in the aspects of surface roughness fluctuation.

The control system was also realized experimentally due to the excellent results of the simulations.

\section{REFERENCES}

[1] Çolak, 0. (2014). Optimization of machining performance in high-pressure assisted turning of Ti6Al4V alloy. Strojniški vestnik - Journal of Mechanical Engineering, vol. 60, no. 10, p. 675-681, Dol:10.5545/sv-jme.2013.1079.

[2] Grigoriev, S.N., Starkov, V.K., Gorin, N.A., Krajnik, P., Kopač, J. (2014). Creep-feed grinding: an overview of kinematics, parameters and effects on process efficiency. Strojniški vestnik - Journal of Mechanical Engineering, vol. 60, no. 4, p. 213-220, D0I:10.5545/sv-jme.2013.1547.

[3] Koren, Y. (1983). Computer Control of Manufacturing Systems. McGraw-Hill, New York.

[4] Stute, G., Goetz, F.R. (1995). Adaptive control system for variable gain in ACC systems. Proceedings of the $16^{\text {th }}$ International Machine Tool Design and Research Conference, Manchester, p. 117-121.

[5] Pitstra, W.C., Pieper, J.K. (2000). Controller designs for constant cutting force turning machine control. ISA Transactions, vol. 39, no. 2, p. 191-203, D0l:10.1016/S00190578(00)00008-2.

[6] Hwang, C.L. (1993). Adaptive turning force control with optimal robustness and constrained feed rate. International Journal of Machine Tools and Manufacture, vol. 33, no. 3, p. 483-493, DOl:10.1016/0890-6955(93)90054-X.

[7] Ruey, J.L. (2012). Intelligent control of a constant turning force system with fixed metal removal rate. Applied Soft Computing, vol. 12, no. 9, p. 3099-3111, D0l:10.1016/j.asoc.2012.05.012.

[8] Daeshmend, L.K., Pak, H.A. (1986). Model reference adaptive control of feed force in turning. ASME Journal of Dynamic Systems, Measurement and Control, vol. 108, no. 3, p. 215222, D0I:10.1115/1.3143770.

[9] Landers, R.G., Ulsoy, G.A. (1998). Supervisory machining control: design approach and experiments. CIRP Annals - Manufacturing Technology, vol. 47, no. 1, p. 301-306, D0I:10.1016/S0007-8506(07)62838-8.

[10] Landers, R.G., Ulsoy, A.G., Ma, Y.-H. (2004). A comparison of model-based machining force control approaches. International Journal of Machine Tools and Manufacture, vol. 44, no.7-8, p. 733-748, D0l:10.1016/j. ijmachtools.2004.02.005.

[11] Tomizuka, M., Oh, J.H., Dornfeld, D.A. (1983). Model reference adaptive control of the milling process. ASME Control of Manufacturing Processors and Robotic Systems, vol. 11, p. 55-64.

[12] Lauderbaugh, L.K., Ulsoy A.G. (1989) Model reference adaptive force control in milling. ASME Journal of Engineering for Industry, vol. 111, no. 1, p. 13-21, Dol:10.1115/1.3188726.

[13] Yamazaki, K., Kojima, N., Sakamoto, C., Saito, T. (1991). Real-time model reference adaptive control of 3-D sculptured surface machining. CIRP Annals - Manufacturing 
Technology, vol. 40, no. 1, p. 479-482, D0l:10.1016/\$00078506(07)62034-4.

[14] Psaltis, D, Sideris, A, Yamamura, A.A. (1988). A multilayered neural network control. IEEE Control Systems Magazine, vol. 8, no.2, p.17-21, Dol:10.1109/37.1868.

[15] Tarng, Y.S., Hwang, S.T., Wang, Y.S., (1994). A neural network controller for constant turning force. International Journal of Machine Tools and Manufacture, vol. 34, no. 4, p. 453-460, DOl:10.1016/0890-6955(94)90077-9.

[16] Zuperl, U., Cus, F. (2004). Tool cutting force modeling in ballend milling using multilevel perceptron. International Journal of Materials Processing Technology, vol. 153-154, p. 268-275, DOI:10.1016/J.jmatprotec.2004.04.309.

[17] Korkut, I., Donertas, M.A. (2007). The influence of feed rate and cutting speed on the cutting forces, surface roughness and tool-chip contact length during face milling. Materials \& Design, vol. 28, no. 1, p. 308-312, D0l:10.1016/j. matdes.2005.06.002.
[18] Brezak, D., Majetić, D., Udiljak, T., Kasać, J. (2014). Tool wear estimation using an analytic fuzzy classifier and support vector machines. Journal of Intelligent Manufacturing, vol. 23, no. 3, p. 797-809, D0l:10.1007/s10845-010-0436-x.

[19] Cus, F., Zuperl, U. (2006). Approach to optimization of cutting conditions by using artificial neural networks. Journal of Materials Processing Technology, vol. 173, no. 3, p. 281-290, DOI:10.1016/j.jmatprotec.2005.04.123.

[20] Zuperl, U., Cus, F. (2003). Optimization of cutting conditions during cutting by using neural networks. Robotics and Computer-Integrated Manufacturing, vol. 19, no. 1-2, p. 189199, D0I:10.1016/S0736-5845(02)00079-0.

[21] Asiltürk, I., Çunkaş, M. (2011). Modeling and prediction of surface roughness in turning operations using artificial neural network and multiple regression method. Expert Systems with Applications, vol. 38, no. 5, p. 5826-5832, Dol:10.1016/j. eswa.2010.11.041. 